\title{
Implicit Memory and Familiarity Among Elders with Dementia
}

\author{
Gwi-Ryung Son, Barbara Therrien, Ann Whall
}

\begin{abstract}
Purpose: To propose a framework for familiar environment as a cue for maintaining or maximizing functional abilities in elders with dementia.

Organizing Construct: The organizing construct is the sense of familiarity. Although a feeling of familiarity can be processed in both explicit and implicit memory in normal populations, it is retrieved more frequently and efficiently in the implicit memory system than through explicit memory in elders with dementia.

Methods: The model was developed using sources identified through a literature search of relevant topics in Medline, PsycInfo, and CINAHL, as well as through clinical observations and experiences.

Conclusions: Evidence from neuro- and cognitive psychology indicates that elders with dementia or Alzheimer's disease (AD) have impaired explicit memory but preserved implicit memory. For initiating an intervention related to spared implicit memory, we propose that implicit memory can be used therapeutically in patients with dementia. The sense of familiarity as a form of implicit memory is used as an exemplar. Producing or introducing the sense of familiarity into a new or strange environment as well as maximizing familiarity in an existing environment is proposed as a viable nursing strategy.
\end{abstract}

Journal of Nursing Scholarship, 2002; 34:3, 263-267. @2002 Sigma Theta Tau International.

[Key words: memory, familiar environment, dementia, Alzheimer's disease]

$\mathbf{S}$ everal scholars have emphasized the important relationships among environment, human health (Kaplan \& Kaplan, 1982; Lawton, 1983; Roberts \& Algase, 1988), and human behavior (Altman \& Werner, 1985). The environment can serve as a cue to remind people to connect present and past, and to link experience and memory (Dovey as cited in Altman \& Werner, 1985). In longterm care facilities, a common wish from elders with dementia is: "I want to go home." Although the staff reminds them that the facility is their home, many elders constantly ask to return to their homes, which may indicate they are not connecting present and past environments. The perceived home is not just a physical place to stay, but it also is a place with psychological, social, and cultural meaning.

The cause of inappropriate behavior is not fully understood. This behavior may be an expression of discomfort and need among cognitively impaired people (Algase et al., 1996; Cohen-Mansfield, 2000), or may be an unconscious coping strategy used by elders striving to achieve external continuity by seeking familiar environments and people (Onega \& Tripp-Reimer, 1997). In general, dementia is a disorder of memory and cognition that occurs when neurons and their connections are damaged. Neural damage might be extensive, but early, consistent, and evolving pathology in brain areas might be responsible for explicit learning, remembering, representing, and reasoning (Braak \& Braak, 1997). Remote memories are more resilient than are recent ones. Thus, elders with dementia have difficulty learning about and interpreting new environments. They may not have the ability to generalize from past to present experiences or to modify cognitive representations, such as old home and new home.

The home environment is thoroughly imbued with the familiarity of past experience (Dovey as cited in Altman \& Werner, 1985). When elders with dementia are admitted to institutional care facilities, they may experience dissonance, confusion, and discomfort because they are not familiar with new surroundings. Do providers understand the cognitively impaired person's discomfort and need? In this paper, "familiarity" is the organizing construct, and this question

Gwi-Ryung Son, RN, PhD, Rho, Assistant Research Scientist; Barbara Therrien, RN, PhD, FAAN, Rho, Associate Professor; Ann Whall, RN, PhD, FAAN, Lambda, Professor, all at University of Michigan School of Nursing, Ann Arbor, MI. This study was funded by NINR Grant T32 NR007074. Correspondence to Dr. Son, University of Michigan School of Nursing, 400 N. Ingalls, Division I, Ann Arbor, MI 48109-0482. E-mail: grson@umich.edu Accepted for publication October 12, 2001. 
is addressed with a focus on the sense of familiarity in care of elders with dementia.

\section{Background}

\section{Familiarity}

Familiarity is defined in this discussion as thorough knowledge of a subject derived from a close relationship and acquaintance from past experience. According to cognitive psychologists Kaplan and Kaplan (1982, p. 92), familiarity is "The relationship between an individual and something that individual has had considerable experience with. The experience is sufficient to advance to the development of an internal model of that something." In addition, "Increasing familiarity leads to the strengthening of connections among less closely connected features that turn out to be more salient. Familiarity thus provides the ways to facilitate the basic process of searching for a solution, and connect startup and goal” (pp. 166-167).

People feel more comfortable and increase their social and functional abilities when they have familiar environments such as places, objects, and sounds (Kaplan \& Kaplan, 1982; Küller, 1988; Liu, Gauthier, \& Gauthier, 1991). Therefore, the feeling of familiarity is the product of repeated and frequent exposure to something (e.g., people, objects, scenes, or sounds). A feeling of familiarity results from the previous experience with something and is based in life's memories, both implicit and explicit. To feel familiar with something, repetition and frequency are critical antecedents. Comfort, prediction, effortlessness, and speed are the cognitive and emotional consequences of the feeling of familiarity (Kaplan \& Kaplan, 1982).

\section{Implicit Memory and Habit in Elders with Dementia}

Memory is the capacity to acquire, retain, and evoke experiences and the effects of experiences (Bachevalier, 1990). Memory has two components: explicit (declarative) and implicit (habit). Explicit memory is conscious, directed effort to recollect prior experience and facts. Implicit memory is the demonstration of the effects of prior experience without conscious recollection of that experience (Graf \& Masson, 1993; Schacter, 1994). Mishkin and Petri (1984) called it habit. Squire (1992) categorized memory as either hippocampal-dependent (i.e., declarative) or hippocampal-independent (i.e., nondeclarative); these terms are used synonymously with explicit and implicit memory, respectively. The preservation of priming, skill learning, and biasing judgments in amnesic patients are all mediated by the nondeclarative form of memory.

Explicit memory classifications can be subdivided into three systems: semantic (spatial and relational), working (visual and auditory), and episodic. Implicit memory is classified as procedural (motor skill, habit, cognitive skill, simple conditioning) or priming and classical conditioning (Schacter \& Tulving, 1994). Procedural memory includes learned behaviors and psychomotor skills such as bicycling, feeding self, and combing hair.
Priming refers to the improved facility for identifying a perceptual object on the basis of a specific prior exposure to an object (Schacter, 1994). It is a form of implicit memory in the sense that it can occur without any conscious or explicit recollection of a previous exposure to a stimulus. One brain system, the perceptual-representation system (PRS), is important for priming effects on the implicit memory test. Schacter (1994) divided the PRS into three subsystems: visual word form, auditory word form, and structural description. The PRS is important in identifying words and objects and the system typically operates in implicit expressions of memory, such as priming (Schacter, 1994). Several studies have shown that elders with Alzheimer's disease (AD) have intact perceptual priming for real words (Balota \& Ferraro, 1996), objects (Fleischman, Gabrieli, Reminger, Vaidya, \& Bennett, 1998), and pictures (Gabrieli et al., 1999).

Many researchers (Butters, Heindel, \& Salmon, 1990; Fleischman et al., 1998; Knight, 1998; Randolph et al., 1995) have found that elders with dementia or AD have intact implicit memory but impaired explicit memory. Knight (1998) studied the recollection (conscious) versus automatic memory process (unconscious) of community-dwelling elders with dementia with mean Mini Mental State Examination (MMSE) scores of 21.6 (range 18-24). Recollection and automatic memory can be considered as explicit and implicit processes, respectively. Knight (1998) demonstrated that the elders had poor recollection while they maintained substantial automatic memory process.

Mishkin, Malamut, and Bachevalier (1984) have proposed that retaining effects of experiences proceeds according to two different neural systems: memory and habit. Memory encompasses both recognition and association and is based on the cortico-limbo-diencephalic circuit (Bachevalier, 1990). These brain areas are severely impaired in people with AD and amnesia (Squire, 1982). The other system, habit, mediates retention of stimulus-response connections and depends on a cortico-striatal circuit (Bachevalier \& Mishkin, 1984). Although amnesic patients are not able to remember recent events or to learn new information, they can learn new habits and skills (Cohen \& Squire, 1980). Given that the medial temporal structures (hippocampus and amygdala) are the most consistently and extensively damaged areas in the AD type of dementia, care strategies based on implicit memories should be more successful.

In studies of both humans and rhesus monkeys, researchers have found that memory and habit are subject to ontogenetic development. Infants are born with the ability to acquire habits and skills while declarative memory matures slowly (Bachevalier, 1990; Bachevalier \& Mishkin, 1984). Thus, for two reasons, patients with dementia or amnesia can maintain previously developed habits and skills. First, a neuroanatomical dissociation of two neural systems is present from infancy in humans (Bachevalier, 1990; Bachevalier \& Mishkin, 1984). Second, these habit and skill systems have already been established prior to limbo-diencephalic injury or disease onset and are typically spared by disease (Cohen $\&$ Squire, 1981). Once the neural representation of stimulus 
and experiences has been achieved, the stored stimulus representation can be retrieved by stimulus cues through a process of associative recall and stimulus-response mechanisms (Mishkin, Malamut, \& Bachevalier, 1984; Mishkin \& Petri, 1984).

\section{Familiarity in Elders with Dementia}

Although Kaplan and Kaplan (1982) did not address familiarity in elders with dementia, they stated that familiarity could increase confidence and speed in cognitively intact people. People perform better and can predict and direct their behaviors when they encounter familiar items or environments (Kaplan \& Kaplan, 1982). People can perceive the feeling of familiarity with or without recognition of the previously encountered stimulus. Familiarity occurs with successful recognition of the encountered stimulus as a result of the explicit memory system operating a search and retrieval process (Squire, 1994). Someone may say, "She is very familiar to me, but I can't remember where I met her before." In this case, people try to connect the feeling of familiarity with conscious memory, but they fail to remember the person at that moment. Later, they may or may not realize a connection between the feeling of familiarity and memory. Squire (1994) said that such a feeling of familiarity without successful recognition is an indication of priming, that is, implicit memory. Another example of the feeling of familiarity is "being suddenly reminded of watching a sunset while listening to a beautiful melody." This is a feeling of familiarity that suddenly occurs without the person making an effort to recollect anything. In this case, the feeling of familiarity has developed unconsciously through implicit memory, the automatic memory process (Graf \& Masson, 1993).

Thus, recognition (memory) is constructed of two different processes, the conscious recollection process that depends on explicit (declarative) memory, and a priming process, which results in feelings of familiarity (Mandler as cited in Squire, 1994). Within the explicit memory system, people perceive the feeling of familiarity with successful recognition, that is "Remember $(\mathrm{R})$ " response, while people can perceive a feeling of familiarity without conscious recall in implicit memory, that is "Know $(\mathrm{K})$ " response.

Studying memory in impaired populations such as elders with dementia or $\mathrm{AD}$ requires understanding of perceptual fluency cues (PFC). PFC occurs from the operation of priming (PRS) and recognition memory (Schacter, 1994). It is distinguished from episodic memory and semantic memory. In this recognition paradigm, participants classify responses by either an " $\mathrm{R}$ " or " $\mathrm{K}$ "; an R response indicates recognition associated with some specific recollection of a target's occurrence in the learning episode, and a $\mathrm{K}$ response designates recognition based on feeling of familiarity with an item without any recollective experience (Dalla Barba, 1997; Jacoby, Yonelinas, \& Jennings, 1996). Thus, the $\mathrm{K}$ response reflects unconscious influences of implicit memory (Jacoby et al., 1996). Elders with AD are more dependent on feelings of familiarity than on conscious recall in both forced-choice and free-recognition tasks.

\section{Conceptual Model}

A conceptual model of familiarity in elders with dementia or $\mathrm{AD}$ is shown in the Figure. It is based on clinical observations and experiences, research literature, and empirical knowledge from other disciplines such as cognitive science and neuropsychology.

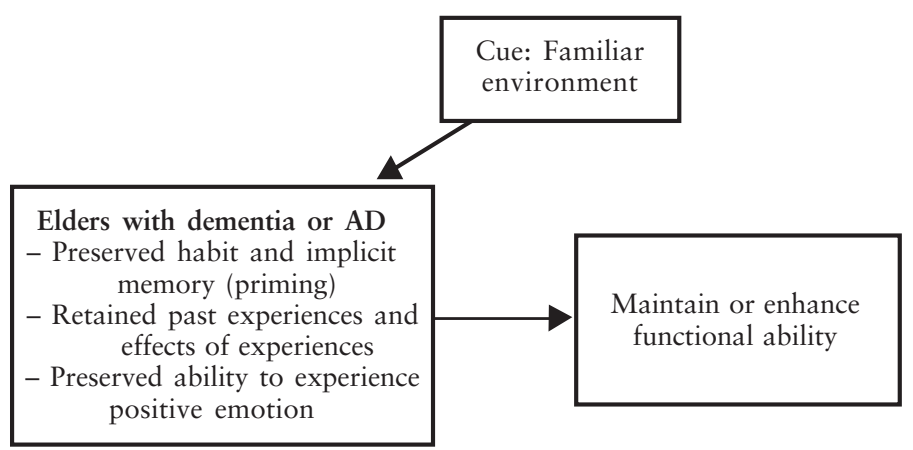

Figure. Conceptual model of familiarity in elders with dementia or AD.

Based on several published theories (Camberg, Woods, \& Mclntyre, 1999; Cohen-Mansfield, 2000; Holden \& Therrien, 1993; Küller, 1988; Roberts \& Algase, 1988), we hypothesize that familiarity (familiar environment) can enhance functional ability (physical, psychological, and emotional abilities) in elders with dementia. Memories, particularly implicit, are inherently linked to behaviors. For example, habits often incorporate repetitive psychomotor actions that can be engaged without conscious thought. Thus, we postulate that exposure to familiar stimuli may spontaneously trigger appropriate functional activities.

In a model involving person-environment interaction (Roberts \& Algase, 1988), functional capabilities are proposed to interact with understanding (i.e. legibility) of the environment in elders with AD. Environmental legibility has two components: cues and stability. Cues provide information about an environment, and stability indicates constancy and familiarity of the cues over time (Roberts \& Algase, 1988). In the case of a patient with $\mathrm{AD}$, the hippocampus in the temporal lobe of the brain is affected. Because the hippocampus is the neural substrate mediating learning of spatial, verbal, and temporal information (Squire, 1992), environmental support is important in order to provide care for disoriented people. Holden and Therrien $(1993 ; 2000)$ used an animal model to examine the effect of familiarity with a single cue in rats with bilateral hippocampus lesions. Their results support the hypothesis that familiarity with a cue prior to hippocampal damage enhances use of the cue after damage. Rats with bilateral hippocampal damage that were familiar with the cue used it more efficiently than did rats with the same damage that were not familiar with the cue. Although this study included an animal model, Holden and Therrien (1993) suggested that research on familiar cues in humans 
with brain damage is warranted. We believe this finding can be adapted to human subjects such as patients with dementia or AD.

In a Swedish experimental study Küller (1988) reported that a familiar environment activated old habits established through participants' lifelong experiences, and as a consequence, it increased functional and social competence among elders with dementia. Further, elders with AD had intact functional spatial skills in a familiar environment, but impaired skills in a new environment (Liu, Gauthier, \& Gauthier, 1991). Functional spatial skills include the use of environmental cues and skills to navigate in familiar and new environments. Johnson and Smith (1998) also found that familiar activities, such as going to a doctor or grocery shopping, affected memory for event schemas in both normal elders and elders with AD. These results show that elders with AD would be best able to perform daily activities with which they were familiar and when daily activities followed a predictable sequential pattern (Johnson \& Smith, 1998). These findings also show that elders with dementia or AD function better in a familiar environment and they receive benefits from a familiar environment when it is a cue.

Camberg and colleagues (1999) said that persons with dementia preserve long-term memories and positive emotions. Therefore, an effective presentation, such as audiotape contact with a family member, could enhance psychological well-being. They developed the intervention of simulated presence (SimPres; Camberg et al., 1999) based on a positive feeling of familiarity. Using an experimental study design with three groups - the intervention group, placebo audiotape, and usual care-in nursing home patients, Camberg and colleagues (1999) found that elders with dementia in the intervention group showed improvement of agitated and withdrawn behaviors. Elders in this group also had a positiveaffect facial expression. Gerdner's $(1999 ; 2000)$ middle-range theory of individualized music intervention for agitation indicated that preferred music stimulates remote memory, and elicitation of memories associated with positive feelings (e.g., happiness and love) will have a soothing effect. These positive feelings, in turn, will decrease agitation among elders with $\mathrm{AD}$ and related disorders. Thus, eliciting positive feelings in people with dementia or AD is an important factor for alleviating behavioral problems such as agitation and withdrawal.

Emotional memory is a form of implicit memory. Activation of the amygdala adds subjective affect to experiences and memories (LeDoux, 1993). As the amygdala is activated, experiences or stimuli are coded with a positive or negative tone, depending on the situation. Although adverse stimuli are more widely studied than are positive stimuli, the rules of association hold. A familiar stimulus is expected to be coupled with a positive emotional pairing. Therefore, when elders with dementia or AD perceive cues with a feeling of familiarity, they tend to experience positive emotions such as a sense of calm, control, or comfort. These positive emotions might make elders with $\mathrm{AD}$ smile, respond better, and become more socially involved.

\section{Conclusions}

Critical relationships among environment, human health, and human behavior are actually memories, and such memories are known to erode in dementia. Thus, the world, one's reliance on it, and behavior within it become increasingly confusing. Although cognitive declines cannot be halted in $\mathrm{AD}$, they can be slowed. We propose that one approach to slowing declines is to use "islands" of preserved memory. One problem is that, in practice, memory is often assumed to be unitary. Research clearly shows this is not the case. To better guide therapeutic approaches as well as research, our intent here is to distinguish between two major forms of memory: explicit (declarative) and implicit (habit). Literature from neuro- and cognitive psychology indicates that elders with mild or moderate dementia or $\mathrm{AD}$ have impaired explicit but preserved implicit memory and habits. For initiating interventions related to spared implicit memory, we introduce the idea that implicit memory can be used therapeutically in people with dementia. The sense of familiarity as a form of implicit memory is used as an exemplar.

Because elders with dementia or $\mathrm{AD}$ are typically unable to learn or interpret a new environment (Camberg et al., 1999), the new intervention should help them to retrieve memories of their preserved past experience using environmental cues. Hence, a familiar environment is important for daily life in cognitively impaired elders, introducing the sense of familiarity into a new or strange environment as well as maximizing familiarity in an existing environment. Therefore, new interventions should be focused on using aspects of prior familiar environments such as smells, music, foods, objects, and pictures, to maximize functional ability in elders with dementia. Although a feeling of familiarity can exist in both explicit and implicit memory in normal populations, it is retrieved more frequently and efficiently via the implicit memory system in elders with dementia. Elders with dementia or AD may not purposefully retrieve encoded long-term memory, but they may instead invoke memories encoded with familiar environmental cues. For testing this theory, further systematic research is needed to determine types of cues, power of cues, and the effects of familiarity on behavior and function in elders with dementia.

\section{References}

Algase, D.L., Beck, C., Kolanowski, A., Whall, A., Berent, S., Richards, K., et al. (1996). Need-driven dementia-compromised behavior: An alternative view of disruptive behavior. American Journal of Alzheimer's Disease, November/December, 10-19.

Altman, I., \& Werner, C.M. (1985). Home environments: Human behavior and environment advances in theory and research. New York: Plenum.

Bachevalier, J. (1990). Ontogenetic development of habit and memory formation in primates. Annals of the New York Academy of Sciences, 608, 457-477.

Bachevalier, J., \& Mishkin, M. (1984). An early and a late developing system for learning and retention in infant monkeys. Behavioral Neuroscience, 98(5), 770-778.

Balota, D.A., \& Ferraro, F.R. (1996). Lexical, sublexical, and implicit memory processes in healthy young and healthy older adults and in individuals with dementia of the Alzheimer type. Neuropsychology, 10, 82-95. 
Braak, H., \& Braak, E. (1997). Diagnostic criteria for neuropathologic assessment of Alzheimer's disease. Neurobiology of Aging, 18(4), S85S88.

Butters, N., Heindel, W.C., \& Salmon, D.P. (1990). Dissociation of implicit memory in dementia: Neurological implications. Bulletin of the Psychometric Society, 28(4), 359-366.

Camberg, L., Woods, P., \& McIntyre, K. (1999). SimPress: A personalized approach to enhance well-being in persons with dementia. In L. Volicer \& L. Bloom-Charette (Eds.), Enhancing the quality of life in advanced dementia (pp. 126-140). Philadelphia: Brunner/Mazel.

Cohen, N.J., \& Squire, L.R. (1980). Preserved learning and retention of pattern analyzing skill in amnesia: Dissociation of "knowing how" and "knowing that." Science, 210, 207-209.

Cohen, N.J., \& Squire, L.R. (1981). Retrograde amnesia and remote memory impairment. Neuropsychologia, 19, 337-356.

Cohen-Mansfield, J. (2000). Heterogeneity in dementia: Challenges and opportunities. Alzheimer Disease and Associated Disorders, 14(2), 6063.

Dalla Barba, G. (1997). Recognition memory and recollective experience in Alzheimer's disease. Memory, 5(6), 657-672.

Fleischman, D.A., Gabrieli, J.D.E., Reminger, S.L., Vaidya, C.J., \& Bennett, D. (1998). Object decision priming in Alzheimer's disease. Journal of the International Neuropsychological Society, 4, 435-446.

Gabrieli, J.D.E., Vaidya, C.J., Stone, M.V., Francis, W.S., Thompson-Schill, S. L., Fleischman, et al. (1999). Convergent behavioral and neuropsychological evidence for a distinction between identification and production forms of repetition priming. Journal of Experimental Psychology: General, 128(4), 479-498.

Gerdner, L.A. (1999). Individualized music intervention protocol. Journal of Gerontological Nursing, 25(10), 10-16.

Gerdner, L.A. (2000). Effects of individualized vs. classical "relaxation" music on the frequency of agitation in elderly persons with Alzheimer's disease and related disorders. International Psychogeriatrics, 12(1), 4965 .

Graf, P., \& Masson, M.E.J. (1993). Implicit memory: New directions in cognition, development, and neuropsychology. Hillsdale, NJ: Lawrence Erlbaum.

Holden, J.E., \& Therrien, B. (1993). Cue familiarity reduces spatial disorientation following hippocampal damage. Nursing Research, 42(6), 338-343.

Holden, J.E., \& Therrien, B. (2000). The effect of familiarity on distraction and single cue after hippocampal damage. Biological Research for Nursing, 1(3), 165-178.

Jacoby, L.L., Yonelinas, A.P., \& Jennings, J. (1996). The relation between conscious and unconscious (automatic) influences: A declaration of independence. In J.D. Cohen \& J.W. Schooler (Eds.), Scientific approaches to the questions of consciousness. Hillsdale, NJ: Lawrence Erlbaum.

Johnson, D.L., \& Smith, S.D. (1998). Effects of familiarity and temporal organization on memory for event schemas in aged and Alzheimer subjects: Implications for clinical management. Alzheimer Disease and Associated Disorders, 12(1), 18-25.

Kaplan, S., \& Kaplan, R. (1982). Cognition and Environment: Functioning in an uncertain world. New York: Praeger.

Knight, R.G. (1998). Controlled and automatic memory process in Alzheimer's disease. Cortex, 34, 427-435.

Küller, R. (1988). Environmental activation of old persons suffering from senile dementia. In H.V. Hoogdalem, N.L. Prak, T.J. van der Voordt, \& H.B.R. van Wegen (Eds.), Looking back to the future, Vol. II: Symposia and papers/symposiums et communications (pp. 133-139). Delft: Delft University Press.

Lawton, M.P. (1983). Environment and other determinants of well-being in older people. The Gerontologist, 23(4), 349-359.

LeDoux, J.E. (1993). Emotional memory systems in the brain. Journal Brain Research, 58, 69-79.

Liu, L., Gauthier, L., \& Gauthier, S. (1991). Spatial disorientation in persons with early senile dementia of the Alzheimer type. The American Journal of Occupational Therapy, 45(1), 67- 74.

Mishkin, M., Malamut, B.L., \& Bachevalier, J. (1984). Memories and habits: Two neural systems. In G. Lynch., L. McGaugh, \& N.M. Weinberger (Eds.), Neurobiology of learning and memory (pp. 65-77). New York: Guilford.
Mishkin, M., \& Petri, H.L. (1984). Memories and habit: Some implications for the analysis of learning and retention. In N. Butters, \& L.R. Squire (Eds.), Neuropsychology of memory (pp. 287-296). New York: Guilford.

Onega, L.L., \& Tripp-Reimer, T. (1997). Expanding the scope of continuity theory: Application to gerontological nursing. Journal of Gerontological Nursing, 23(6), 29-35.

Randolph, C., Tierney, M.C., \& Chase, T.N. (1995). Implicit memory in Alzheimer's disease. Journal of Clinical and Experimental Neuropsychology, 17(3), 343-351.

Roberts, B.L., \& Algase, D. (1988). Victims of Alzheimer's disease and the environment. Nursing Clinics of North America, 23(1), 83-93.

Schacter, D.L. (1994). Priming and multiple memory systems: Perceptual mechanisms of implicit memory. In D.L. Schacter \& E. Tulving (Eds.), Memory systems (pp. 233-268). Cambridge, MA: MIT Press.

Schacter, D.L., \& Tulving, E. (1994). What are the memory systems of 1994? In D. L. Schacter \& E. Tulving (Eds.), Memory systems (pp. 1-38). Cambridge, MA: MIT Press.

Squire, L.R. (1982). The neuropsychology of human memory. Annual Review of Neuroscience, 5, 241-273.

Squire, L.R. (1992). Declarative and nondeclarative memory: Multiple brain systems supporting learning and memory. Journal of Cognitive Neuroscience: Special Issue: Memory Systems, 4, 232-243.

Squire, L.R. (1994). Declarative and nondeclarative memory: Multiple brain systems supporting learning and memory. In D.L. Schouter \& E. Tulving (Eds.), Memory systems (pp. 203-231). Cambridge, MA: MIT Press. 